\title{
CONDITIONS OF HOUSING INFRASTRUCTURE BEFORE THE OCCURRENCE OF AN EARTHQUAKE
}

\author{
VALERIA SCAPINI $^{1} \&$ EDUARDO ZUÑIGA $^{2}$ \\ ${ }^{1}$ Centro de Investigación en Innovación, Desarrollo Económico y Políticas Sociales (CIDEP), \\ Universidad de Valparaíso, Chile \\ ${ }^{2}$ Complex Engineering Systems Institute (ISCI), Universidad de Chile, Chile
}

\begin{abstract}
Natural disasters generate great economic costs related to damaged houses or loss of infrastructure. In this context, the case of Chile is particularly interesting, as it is located in the "Pacific Ring of Fire" and is considered one of the most seismically active countries in the world. Based on the evidence from the 2010 earthquake, an empirical study was carried out using the panel survey CASEN Post earthquake. We model a Markov chain whose states represent housing conditions (good, regular and bad) and where each instance of the chain corresponds to the occurrence of an earthquake. For this model, we calculate the transition probabilities of moving from one state to another and find the stationary probabilities of the chain. We interpret these probabilities as the percentage of time that houses spend in each state in the long term. We propose a method to calculate the expected cost of full reconstruction of houses. This information could be useful to policy makers for evaluating if it is necessary to repair the damage or wait for the destruction of the house and rebuild it.
\end{abstract}

Keywords: natural disasters, earthquake, Markov chain, damage assessment, reconstruction cost.

\section{INTRODUCTION}

Natural disasters such as earthquakes generate significant damage or loss of houses that are related to a significant cost associated with the reconstruction process. Chile is considered one of the most seismically active countries in the world; in this sense, it is very important to understand the destructive power of this type of disaster, in order to generate adequate public policies related to reconstruction. This paper examines these issues.

We focus on the 2010 Chilean earthquake, as it is very special for at least three reasons. First, Chile is a country prone to destructive earthquakes. Second, the earthquake that hit Chile on 27 February 2010, with a magnitude of 8.8 on the moment magnitude scale, ranks as one of the strongest earthquakes ever recorded and it affected considerably 6 out of 13 Chilean regions. Finally, because we have a panel data at the household level that allow us to assess the damage caused by the earthquake.

With this information, we model a Markov chain whose states represent housing conditions and where each transition of the chain corresponds to the occurrence of an earthquake. The major objectives of the work are to calculate the transition probabilities of moving from one state to another, find the stationary probabilities associated to the chain, and finally propose a method to analyse the trade-off faced by the policy maker between partial reconstruction before an event versus full reconstruction after the event.

The remainder of the paper is organized as follows. Section 2 presents briefly the Chilean context; Section 3 presents the data collection. Section 4 addresses the mathematical modelling and results. Section 5 studies some possible extensions of our paper and finally, the conclusions are highlighted in Section 6.

\section{CHILEAN CONTEXT}

Earthquakes occur in areas of the planet in which the surface is limited by tectonic plates, and as they move, they cause deformations in the rocks on both sides. Earthquakes occur 
releasing astonishingly big amounts of energy in the form of heat and as shock waves that form the earthquake [1], [2]. In this context, Chile is world-wide one of the countries with the highest seismic activity because it is located in the well-known "Pacific Ring of Fire", an area where tectonic plates are in permanent friction [3], [4]. This makes Chilean experience extremely valuable in the context of disaster management.

Among the main events, the earthquake of February 27, 2010 stands out with a magnitude of 8.8 on the Richter scale. It was the second strongest earthquake in the history of the country and number six at world level [5]. The epicentre was located $8 \mathrm{~km}$ west of Curanipe, began at 03:34 a.m. local time and it lasted approximately 3 minutes. It affected a distance of approximately 700 kilometres. This fact is quite important as this region is where about $80 \%$ of the country's population live. Nearly 500 thousand houses were affected. After the event, local seismic regulations were updated to improve construction safety levels [6].

\section{DATA COLLECTION}

We use a panel data called The National Post-Earthquake Socioeconomic Characterization Survey. This survey was commissioned by the Ministry of Planification of Chile, with the purpose of evaluating the changes in the level of life of the people affected by the 2010 earthquake and tsunami. Data collection was made by Observatorio Social Universidad Alberto Hurtado between May and June 2010. It contains information of 22,456 households, which is a subset of the CASEN survey made on 2009. Therefore, this is a longitudinal survey with national and regional representativity. The National Post-Earthquake Socioeconomic Characterization Survey was done by the application of a questionnaire in each household and collects information about each member of the house. This questionnaire was completed in a direct interview. This method has two main advantages. In the first place it promotes the trust between pollster and respondent, and secondly, it allows the pollster to explain and guide the respondent through some questions that might be complex. The information was provided by the same person that answered the CASEN 2009 survey or, if that person was not available, another adult in the house.

This database contains information on household conditions in two different times: before and after the occurrence of the disaster. On one hand, we can see that in the period prior to the disaster, $78.8 \%$ of households had good conditions. This means that the floor, walls and roof are in good condition. On the other hand, we can see that the $21.2 \%$ of households had regular conditions. This means that at least one of the three previous structures (floor, walls or roof) was in poor condition.

This database does not contain information about houses that were destroyed before the earthquake. The descriptive statistics of the number of houses according to the level of damage in the period prior to the earthquake are shown in Table 1.

Table 1: Number of houses according to the level of damage in the period prior to the earthquake.

\begin{tabular}{|l|c|c|c|c|}
\hline \multirow{2}{*}{ Conditions } & \multicolumn{2}{|c|}{ All provinces } & \multicolumn{2}{c|}{ Affected provinces } \\
\cline { 2 - 5 } & $\mathrm{N}^{\circ}$ of houses & $\begin{array}{c}\text { Percentage } \\
(\%)\end{array}$ & $\mathrm{N}^{\circ}$ of houses & $\begin{array}{c}\text { Percentage } \\
(\%)\end{array}$ \\
\hline Good & 17,441 & 78.8 & 13,872 & 78.7 \\
\hline Regular & 4,693 & 21.2 & 3,763 & 21.3 \\
\hline Bad & 0 & 0 & 0 & 0 \\
\hline Total & 22,134 & 100 & 17,635 & 100 \\
\hline
\end{tabular}


The descriptive statistics of the number of houses according to the level of damage in the period post the earthquake are shown in Table 2.

Table 2: Number of houses according to the level of damage in the period post to the earthquake.

\begin{tabular}{|l|c|c|c|c|}
\hline \multirow{2}{*}{ Conditions } & \multicolumn{2}{|c|}{ All provinces } & \multicolumn{2}{c|}{ Affected provinces } \\
\cline { 2 - 5 } & $\mathrm{N}^{\circ}$ of houses & $\begin{array}{c}\text { Percentage } \\
(\%)\end{array}$ & $\mathrm{N}^{\circ}$ of houses & $\begin{array}{c}\text { Percentage } \\
(\%)\end{array}$ \\
\hline Good & 14,625 & 66.8 & 10,280 & 59.0 \\
\hline Regular & 6,565 & 30.0 & 6,447 & 37.0 \\
\hline Bad & 709 & 3.2 & 709 & 4.1 \\
\hline Total & 21,899 & 100 & 17,436 & 100 \\
\hline
\end{tabular}

\section{MATHEMATICAL MODELING AND RESULTS}

We model the information of the transition of one house condition to another as a Markov chain, whose states are: $E=$ good, regular, bad. This classification refers to the state of the household before and after the event.

- Good: Not affected or minor damages

- Regular: Major damages

- Bad: Destroyed or in need to be demolished

Those definitions came from a classification of the answers of the people to the CASEN survey. In one of the questions, people needed to answer specifically in which condition their house was.

Each realization of the chain corresponds to the occurrence of an event, in this case an earthquake. What we do in this model is to calculate the transition probabilities of the chain, and then use them to find the stationary distribution, which represents the percentage of time that the chain spends in each state in the long term.

\subsection{Transition probabilities}

We compute the transition probabilities between states considering the state of the household before and after the earthquake, and then applying favourable over total cases. Formally, let $N_{i, j}$ be the number of households that went from state $i$ to state $j$ because of the event, and $N$ the total number of households in the sample. The probabilities of transition between states are calculated as follows:

$$
p_{i, j}=\frac{N_{i, j}}{N} \forall i, j \in E .
$$

We name $A=\left(p_{i, j}\right)_{i, j \in E}$ the matrix of this markov chain. 
After some computations, it is possible to show that the transition probabilities are as indicated in Tables 3 (all regions) and 4 (affected regions), where state 0 is Good, state 1 is Regular and state 2 is Bad.

Table 3: Transition probabilities in all regions.

\begin{tabular}{|l|c|c|c|c|}
\hline \multirow{2}{*}{$\begin{array}{l}\text { Period prior } \\
\text { earthquakes }\end{array}$} & \multicolumn{4}{|c|}{ Period post-earthquakes } \\
\cline { 2 - 5 } & 0 & 1 & 2 & \multirow{2}{*}{ Total cases } \\
\hline \multirow{2}{*}{0} & 12,125 & 4,697 & 435 & 17,257 \\
\cline { 2 - 5 } & 70.26 & 27.22 & 2.52 & - \\
\hline \multirow{2}{*}{1} & 2,500 & 1,868 & 274 & 4,642 \\
\cline { 2 - 5 } & 53.86 & 40.24 & 5.90 & - \\
\hline \multirow{2}{*}{ Total } & 14,625 & 6,565 & 709 & 21,899 \\
\cline { 2 - 5 } & 66.78 & 29.98 & 3.24 & - \\
\hline
\end{tabular}

Table 4: Transition probabilities in affected regions.

\begin{tabular}{|c|c|c|c|c|}
\hline \multirow{3}{*}{$\begin{array}{l}\text { Period prior } \\
\text { earthquakes }\end{array}$} & \multicolumn{4}{|c|}{ Period post-earthquakes } \\
\hline & \multicolumn{3}{|c|}{ Level of damage } & \multirow{2}{*}{ Total cases } \\
\hline & 0 & 1 & 2 & \\
\hline \multirow{2}{*}{0} & 8,659 & 4,624 & 435 & 13,718 \\
\hline & 63.12 & 33.71 & 3.17 & - \\
\hline \multirow{2}{*}{1} & 1,621 & 1,823 & 274 & 3,718 \\
\hline & 43.60 & 49.03 & 7.37 & - \\
\hline Total & 10,280 & 6,447 & 709 & 17,436 \\
\hline
\end{tabular}

Summarizing, we have:

$$
\begin{aligned}
& p_{0,0}=0.70, \quad p_{0,1}=0.27, \quad p_{0,2}=0.03 \\
& p_{1,0}=0.54, \quad p_{1,1}=0.40, \quad p_{1,2}=0.06, \\
& p_{2,0}=0.01, \quad p_{2,1}=0.00, \quad p_{2,2}=0.99
\end{aligned}
$$

It should be noted that we set $p_{2,1}=0$ because we assume that in case of personal effort, the reconstruction is full. Note that $p_{2,0}>0$, which can appear counter intuitive at first sight. The reason behind this fact is that we are considering that a small portion of the houses are repaired by their owners after the event. We will go deeper in this assumption in the Extensions section.

\subsection{Stationary state}

Once we have defined the transition probabilities it is possible to look for the stationary state vector, which is defined as vector such that [7]:

$$
\mathbf{A} \boldsymbol{\pi}=\boldsymbol{\pi},
$$


where $\mathbf{A}$ is the transition matrix of the chain. That is, the stationary vector $\boldsymbol{\pi}$ is an eigenvector of $\mathbf{A}$ associated with the eigenvalue 1. For the existence of this vector $\boldsymbol{\pi}$ we need to ensure two conditions:

(a) A to be irreducible.

(b) All the states in $E$ must be positive recurrent and aperiodic.

Matrix $\mathbf{A}$ being irreducible means that all the states are communicated, and we assume this since a house can deteriorate or improve with the pass of time. The second characteristic is true, since it is always possible to come back to every state with no regularity in the number of steps (aperiodic). Therefore, in the remainder of the paper we assume that the chain has these two characteristics.

Using the transition probabilities found in the previous section, we have the following linear system for $\pi$ :

$$
\begin{gathered}
0.27 \pi_{2}+0.03 \pi_{3}=0.3 \pi_{1} \\
0.54 \pi_{1}+0.06 \pi_{3}=0.6 \pi_{2} \\
0.01 \pi_{1}=0.1 \pi_{3} .
\end{gathered}
$$

After some computations, it is possible to find the stationary state probabilities:

$$
\pi_{1}=0.14, \pi_{2}=0,06, \pi_{3}=0.8 \text {. }
$$

We interpret these probabilities as the proportion of time the chain spends in each state.

\section{EXTENSIONS}

We would like to use this methodology to estimate the unit long term cost of reconstruction and thus, inform the policy maker when is the best moment for the government to act. In order to do so, the first step is to define what we understand as the unit long term cost of reconstruction. In this case, we consider the following function:

$$
C=\pi_{1} * v_{1}+\pi_{2} * v_{2}+\pi_{3} * v_{3},
$$

where $v_{i}$ is the average cost of reconstruction (in dollars), given the state of the house. We obtained these values from CASEN survey. Using the stationary probabilities obtained in Section 4, we have that the expected cost of reconstruction is:

$$
C=0.14 * 0+0.06 * 421.25+0.80 * 3,151.36=\$ 2,538.79 .
$$

Note that this is the expected cost of reconstruction per house.

As we have seen throughout the paper, the model is extremely sensitive to the transition probabilities, i.e., with different assumptions leading to different $p_{i, j}$ we would obtain dramatic variations on the expected cost. In that sense, we propose two extensions that are worthy to consider.

\subsection{Partial reconstruction}

In Section 4, we set $p_{2,0}=0.01$ and said that this expressed the reconstruction immediately after the event. It is reasonable to think that the most affected houses are precisely those which belong to the poorest people. In that sense, it is also reasonable think that the owners of some houses do not have the possibility to rebuild the house. Instead, it is more likely for them to partially reconstruct the building. In our model, we consider for this case that $p_{2,0}=$ 0 and $p_{2,1}=0.01$. Considering this, the new transition probabilities are: 


$$
\begin{gathered}
p_{0,0}=0.7, \quad p_{0,1}=0.27, \quad p_{0,2}=0.03 \\
p_{1,0}=0.54, \quad p_{1,1}=0.4, \quad p_{1,2}=0.06 \\
p_{2,0}=0, \quad p_{2,1}=0.01, \quad p_{2,2}=0.99
\end{gathered}
$$

This leads to

$$
\pi_{1}=0.13, \pi_{2}=0,07, \pi_{3}=0.8 .
$$

Using those last stationary probabilities, the expected cost of reconstruction is:

$$
C=0.13 * 0+0.07 * 421.25+0.80 * 3,151.36=\$ 2,542.14,
$$

which is slightly above the cost of the case with no partial reconstruction. We found this result logical because the most damaged people are more likely to have house destruction, and in the case that these people make an effort to improve their house conditions, it is likely that this improvement might not be enough to fully prepare the house for an earthquake.

\subsection{Government intervention}

In this case, we consider that the government or the respective policy maker takes action before the occurrence of an event, deciding to repair some of the already damaged houses. In our model, this is reflected by a change in the transition probabilities, because now there will be a greater number of constructions in good condition before the event. To reclassify these new good houses, we use the previous transition probabilities, because it is the best approximation that we can get with the current data.

$$
\begin{gathered}
p_{0,0}=0.7, \quad p_{0,1}=0.27, \quad p_{0,2}=0.03 \\
p_{1,0}=0.69, \quad p_{1,1}=0.24, \quad p_{1,2}=0.08 \\
p_{2,0}=0.01, \quad p_{2,1}=0, \quad p_{2,2}=0.99
\end{gathered}
$$

This leads to

$$
\pi_{1}=0.15, \pi_{2}=0,05, \pi_{3}=0.8 \text {. }
$$

Using those last stationary probabilities, the expected cost of reconstruction is:

$$
C=0.15 * 0+0.05 * 421.25+0.80 * 3,151.36=\$ 2,538.51,
$$

which is lower than the cost with no intervention. Although it is slightly different, it is important to mention that we are making a worst-case analysis, since we are considering that the government intervention only allows houses in Regular condition to stay in that condition after the event. If we consider that it is possible to prevent Regular houses from going to Bad, the cost difference only grows. In this new case, the transition probabilities are

$$
\begin{gathered}
p_{0,0}=0.70, \quad p_{0,1}=0.27, \quad p_{0,2}=0.03 \\
p_{1,0}=0.69, \quad p_{1,1}=0.31, \quad p_{1,2}=0.00 \\
p_{2,0}=0.01, \quad p_{2,1}=0, \quad p_{2,2}=0.99
\end{gathered}
$$

This leads to

$$
\mathrm{C}=\$ 2,524.49 \text {. }
$$

An even more complete analysis would be possible by sensitizing all the possible partial reconstruction effects, in particular, the proportion of houses that change their state before an earthquake, because of the intervention of the policy maker. 


\section{CONCLUSIONS}

This work allows one to calculate the transition probabilities of moving from one state to another and find the stationary probabilities. We interpret these probabilities as the percentage of time that households will be in each state in the long term. Using these probabilities, it is possible to define an expected cost of reconstruction for each house. We find that this expected cost decrease with each intervention of the government before the occurrence of an earthquake. In that sense, we establish a method to analyse the trade-off between full reconstruction after the event versus partial solutions before the event. In particular, it will be always beneficial for the policy maker to intervene before the event, as long as the intervention cost is lower than the expected cost of full reconstruction.

\section{REFERENCES}

[1] Pérez, E. \& Thompson, P., Natural hazards: Causes and effects: Lesson 2 - earthquakes. Prehospital and Disaster Medicine, 9(4), pp. 260-272, 1994.

[2] Naghii, M., Public health impact and medical consequences of earthquakes. Revista Panamericana de Salud Pública, 18, pp. 216-221, 2005.

[3] Alvarez, G., Ramirez, J., Paredes, L. \& Canales, M., Zonas oscuras en el sistema de alarma de advertencia de tsunami en Chile. Ingeniare. Revista Chilena de Ingeniería, 18(3), pp. 316-325, 2010.

[4] Shabnam, N., Natural disasters and economic growth: A review. International Journal of Disaster Risk Science, 5(2), pp. 157-163, 2014.

[5] USGS, 20 largest earthquakes in the world. www.usgs.gov/natural-hazards/earthquakehazards/science/20-largest-earthquakes-world. Accessed on: 15 Mar. 2019.

[6] OPS, El Terremoto y Tsunami del 27 de Febrero en Chile: Crónicas y Lecciones Aprendidas en el Sector Salud. Organización Panamericana de la Salud: Santiago de Chile, 2010.

[7] Ross, S.M., Stochastic Processes, John Wiley \& Sons: New York, 1996. 